\title{
Li Po e Mao Tse-Tung em português
}

Sérgio Medeiros

O poeta e tradutor Haroldo de Campos (1929-2003) "reimaginou", em língua portuguesa, a poesia clássica da China. Publicada originalmente em 1996, a antologia Escrito sobre jade, acrescida de novas traduções de sua autoria, saiu em segunda edição apenas em 2009. A novidade, que comentarei, é a inclusão de poemas "clássi$\cos ^{\prime \prime}$ do líder revolucionário Mao Tse-tung. Mas, a meu ver, os poemas de Li Po, que já constavam da primeira edição, ainda são o ponto culminante desse pequeno volume.

O lúcido e irrequieto Haroldo indaga, num texto inserido quase no final da antologia (pena que, em edição tão cuidadosa, as letras das partes em prosa sejam incompreensivelmente miúdas): "Como fazer para que essa poesia, procedente de uma linguagem isolante, monossilábica, de sintaxe posicional, resulte eficaz em idiomas analítico-discursivos, mais lógicos do que analógicos, mais hipotáticos do que paratáticos?" (CAMPOS, 2009, p. 97-98).

Para obter, em português, versos poeticamente eficazes, que correspondessem ao seu exigente padrão de poesia, o tradutor recorreu, nessas versões, a um procedimento hiperpoundiano, que comentarei a seguir.

Mas talvez seja necessário, antes de mais nada, apresentar, em poucas linhas, o poema chinês clássico, ou, pelo menos, alguns no- 
mes exponenciais do período literário em questão, destacando, a partir daí, certos temas e procedimentos recorrentes.

A Anthologie de la poésie chinoise classique, de Paul Demiéville, traz informações sucintas sobre a vida de todos os poetas que integram essa obra extensa. Folheando-a ao acaso, chamou-me a atenção, por um ou outro aspecto trágico, a biografia de Wen Tseu-cheng, alto funcionário da dinastia Wei do Norte, acusado de traição e que morreu na prisão, em 547 d.C. Era considerado, então, um dos maiores autores do seu tempo. Depois dele, deparei-me com o poeta Siue Tao-heng (540-609), que adquiriu ainda jovem a reputação de grande letrado e depois cometeu suicídio por ordem do imperador.

Já na dinastia T'ang, a época de ouro da poesia chinesa, caberia citar, naturalmente, Tu Fu (712-770), um dos maiores da China, amigo e parceiro de Li Po. Levando vida errante e miserável, Tu Fu fracassou em suas tentativas de conseguir um cargo na administração imperial, aspiração que compartilhou com outros poetas, inclusive $\mathrm{Li} \mathrm{Po}$, a respeito de quem falarei mais à frente. $\mathrm{O}$ poeta e pintor Wang Wei (701-761), ao contrário, foi bem-sucedido em sua vida pública e chegou a ser nomeado secretário de Estado pelo imperador Hiuan-tsong.

Alguns poetas chineses desse período preferiram, porém, a solidão, tornando-se eremitas no seio de uma natureza intocada. Um exemplo é Kia Tao, que viveu no final do século VIII. Em certos períodos de sua vida, $\mathrm{Li}$ Po, como falarei, adotou igualmente o modo de vida do eremita.

Li Yu (937-978), cabe destacar, era poeta de grande reputação, e foi - o que não é menos digno de nota - o último imperador da dinastia T’ang. Seu império foi destruído em 975, e ele morreu na prisão. O exílio, o isolamento, a derrota... são temas que aparecem em seus textos e nos versos de outros grandes autores dessa época, 
como os já mencionados Tu Fu e Li Po, que formam, ao lado de Wang Wei, a tríade dos gênios poéticos da China clássica.

Se considerarmos a era seguinte, a da dinastia Song, veremos que os poetas conheceram, como sempre, glória e miséria. Tchang Lei (1052-1112) foi duas vezes banido para longe da capital por haver pranteado de forma muito efusiva seu antigo protetor, que caíra em desgraça - ninguém menos do que o poeta Sou Che, que teve atribulada carreira política, na qual desgraças e exílios se alternaram com grandes êxitos. Sou Che descobriu e protegeu vários poetas e era, por isso, muito querido por seus pares.

Lou Yeou (1125-1210), por sua vez, não apenas ocupou postos diversos, como também caiu nas graças do imperador Hiao-tsong, tornando-se seu protegido. Contudo, não chegou a ser o modelo de funcionário bem-sucedido, pois preferia contemplar a natureza e escrever poesia a levar a sério sua carreira na administração imperial.

As mulheres, obviamente, também escreviam poesia, e a mais célebre autora clássica foi Li Ts'ing-tchao (1084-1141). Colecionou objetos antigos e obras de arte, e durante a invasão dos Kin, quando teve de fugir às pressas, levou consigo toda a sua vasta coleção. Sua vida conjugal feliz inspirou-lhe poemas até hoje lidos e apreciados.

Para não me alongar demais neste breve e lacunar inventário de vidas "poéticas", saltarei até a dinastia Ming, a fim de citar mais um destino trágico (viés incontornável desta minha seleção), o do poeta Kao K'i (1336-1374), que levou vida agitada e acabou executado em praça pública, como cúmplice de um funcionário condenado pelo imperador.

Quero encerrar o inventário, finalmente, citando os poetas Fank'i e T'ong-jouen, sobre os quais quase nada se sabe, exceto que foram monges budistas. A vida de ambos, aparentemente, foi mais calma do que as vidas citadas anteriormente. Como o poeta Wou Kia-ki (1618-1685), que era indiferente a cargos públicos, eles também escolheram viver na pobreza. 
A antologia de Haroldo de Campos destaca a poesia da dinastia T'ang, por isso irei comentar, agora, a biografia do poeta máximo desse período, Li Po (701-762), sobre quem ainda nada disse, embora seja o poeta chinês mais célebre no Ocidente. Li Po é também conhecido por Rihaku (Li Tai Po), leitura japonesa de seu nome. É assim que ele aparece, por exemplo, na famosa antologia de Ezra Pound, Cathay, de 1915, mais tarde incluída no volume Personae, que reúne seus poemas curtos, inclusive as traduções, ou recriações.

Na sua época, Li Po era chamado de "Imortal exilado na terra", levou vida boêmia, mas, por curto período, foi acolhido na corte, onde gozou de enorme consideração. Envolvido por acaso numa rebelião, foi depois exilado, porém, logo mereceu o perdão imperial. Segundo a lenda, morreu bêbado, numa noite de luar, ao tentar agarrar o reflexo da lua no Rio Azul. Deve-se acrescentar que, em 712, ganhou o poder o imperador Xuan-zong, que, durante três décadas, se revelou um dos mais brilhantes soberanos da dinastia T'ang e, sem dúvida, de toda a história da China. Li Po usufruiu dessa época feliz.

Na biografia literária que lhe dedicou Ferdinand Stoces, Le ciel pour couverture, la terre pour oreiller, encontrei alguns dados de interesse que, acredito, mereceriam ser apresentados ao leitor, a fim de que certos aspectos relevantes da vida e da poesia de Li Po, além daqueles já mencionados acima, possam ser trazidos à luz. Serão úteis, certamente, para comentar o alcance literário da antologia Escrito sobre jade, de Haroldo de Campos.

Li Po provém de uma família de mandarins muito antiga, e foi, ao longo de sua vida, um grande viajante, permanecendo geralmente muito pouco tempo num mesmo lugar. (Seja dito, entre parênteses, que o grande poeta japonês Bashô - "Bananeira" é a tradução do seu nome - admirava imensamente tanto a vida quanto a obra de Li Po, "Ameixa Branca", inspirando-se nele, sobretudo, para realizar suas famosas viagens pelo país, a mais longa e importante delas registrada em seu diário Oku-no-Hosomichi, "Caminho estreito para um lugar distante", em que reuniu prosa e poesia (haiku), ci- 
tando ainda textos chineses clássicos.) Essa vida errante, de semterra, não era motivada apenas pelo desejo de dedicar-se à poesia e à contemplação, opção de tantos outros poetas chineses, mas visava, também, fazer reviver uma tradição familiar ancestral, a dos chefes militares, um dos temas da poesia de Li Po. Reza a lenda que, em algumas circunstâncias especiais, o poeta agiu como xia, justiceiro, servindo-se de sua própria espada para restabelecer a ordem. Sua concepção sobre o justiceiro está exposta em certos versos, poderse-ia citar, por exemplo, a famosa "Canção do cavalo branco", que fala de um herói patriota e providencial.

Provavelmente, Li Po era "mestiço", pois seus ancestrais sofreram reveses políticos e foram, então, exilados ou se estabeleceram nos confins do Império, mantendo, desse momento em diante, intenso contato com os "bárbaros" da fronteira (turcos, mongóis e outros povos). Uniram-se, finalmente, a eles, a fim de melhor enfrentar as condições de vida adversas nessas regiões periféricas. Em seus poemas, Li Po descreverá com respeito e admiração a população bárbara, o que só acentua as convicções pacifistas do grande poeta, "eterno exilado", que descreveu em detalhes os horrores das guerras e reavaliou a questão da defesa das fronteiras, embora não se furtasse também - e isso precisa ser dito aqui - a denunciar, quando julgava necessário, o "agressor", fosse ele quem fosse, levantando sua voz contra os massacres que se cometeram e se cometiam ainda na China.

Sabe-se que, entre os ancestrais de Li Po, também houve místicos, a ponto de ele se considerar, com toda a convicção, descendente de Laozi, o lendário fundador do taoísmo, corrente filosóficoreligiosa à qual aderiu ardentemente, adicionando a ela, como era costume na época, alguns princípios do budismo.

Talvez, para Li Po, mais crucial do que recuperar para a sua família o prestígio perdido, ou a glória do mandarim, fosse sua incansável busca pessoal de realização mística, simbolizada pela aquisição do "elixir da imortalidade". Sua ânsia por imortalidade está exposta em seus poemas biográficos, nos quais a sua adesão ao

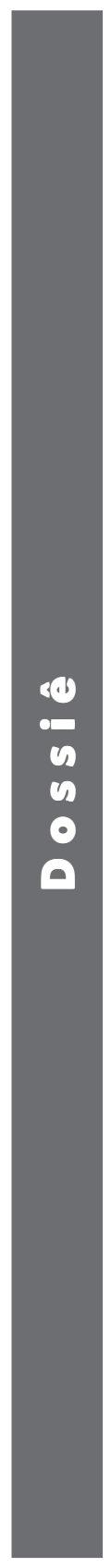


taoísmo é mais que evidente, uma filosofia menos rígida (e, portanto, mais congenial ao seu espírito) do que a doutrina de Confúcio (muito ancorada na realidade), que ele, como os homens do seu tempo, também estudou com afinco. Segundo Ferdinand Stoces, o que o atraía no taoísmo era, sobretudo, a noção de que, no centro de tudo, estaria o indivíduo, e que este gozaria de uma liberdade sem limites. O indivíduo devia buscar a harmonia consigo mesmo, a harmonia com a natureza e com o universo. Desde jovem, Li Po sentiu paixão pelas montanhas, um dos temas máximos da sua poesia, e sempre buscou os mais elevados cumes, a fim de passar ali temporadas contemplando e meditando, rodeado de nuvens e visões de dragões e outros seres fantásticos. Chegou a afirmar, certa vez, que, numa dessas temporadas no alto, pássaros vinham comer na palma de sua mão, sem nenhum receio, prova de que conseguira fundir-se com a natureza e alcançara a liberdade que só os grandes montes proporcionam aos homens. Era chamado, compreensivelmente, de "o ermitão do Lótus azul".

Se, em suma, o poeta se entusiasmava com a possibilidade de adquirir, como desejava seu pai, "o chapéu de seda e a carruagem do mandarim", por outro lado, ele também se sentia apto (jamais fora considerado um "nobre", suas origens, como sabemos, eram obscuras, e seu pai, apenas um comerciante) a alcançar a "iluminação" taoísta. Ao mesmo tempo, ia escrevendo excelente poesia, admirada por todos. Sempre foi considerado um grande poeta. Sua fama de bom músico e cantor também era sólida. Por isso, Stoces concluiu que, ao longo de toda sua vida adulta, Li Po foi seduzido tanto pelo prestígio e realização social quanto pela busca de solidão e iniciação religiosa.

Enfim, dilacerado sempre por sentimentos contraditórios (que definem, por assim dizer, a dupla faceta da sua personalidade), $\mathrm{Li}$ Po, ainda jovem, pôs os pés na estrada, para fazer a descoberta do mundo e, talvez, buscar a imortalidade, encerrada no "elixir" mítico. 
Ao cantar os prazeres da vida, Li Po deu grande destaque às relações com o sexo feminino. Sabe-se que o poeta casou-se quatro vezes e teve vários filhos.

Tal como sucedia com seus contemporâneos, ele prezava, no sexo oposto, particularmente a pele de brancura imaculada, mas também destacava, em seus poemas eróticos, os olhos brilhantes e os pés e as mãos pequenos. Na dinastia T'ang, os poetas costumavam expressar seus sentimentos em relação à mulher de forma indireta, conforme exigia a tradição, imaginando que eram elas, as esposas ou amantes, que se dirigiam a eles, nos poemas, e não o contrário, a fim de manifestar livremente sua saudade ou propor um encontro. Essa "voz feminina" artificial, ou abstrata, como não poderia deixar de ser, aparece com freqüência na poesia de Li Po, embora, em uma ou outra ocasião, ele tenha transgredido essa norma, dirigindo-se diretamente à mulher ausente com franqueza e sinceridade.

Nessa época, seja dito en passant, as cortesãs eram parte integrante da sociedade e seu papel às vezes chegava a ser importante: algumas sabiam ler e escrever, conheciam literatura e também compunham versos. Em resumo, além de musas de pele alva eram, em certa medida, também poetas consumadas. A segunda esposa de $\mathrm{Li}$ Po, como é fama, lia e escrevia muito bem, e teria sido, acredita-se, uma cortesã conceituada, ou admirada, tanto por sua beleza quanto pelos dotes artísticos.

Como já foi afirmado, Li Po teve vários filhos. Não lhe era fácil sustentar a família, uma vez que, na China de então, ninguém considerava - sobretudo os próprios poetas - que a criação literária pudesse ser uma atividade remunerada. Conforme sublinha Ferdinand Stoces, os autores reputados os melhores obtinham a consideração (às vezes, a admiração) da sociedade, mas essa estima social não lhes assegurava renda que lhes possibilitasse viver com dignidade. Li Po, o mais admirado poeta da sua época, não conseguiu superar a penúria econômica, embora tivesse buscado, como outros poetas, um posto na administração imperial, ou mesmo no exército. Daí se compreende melhor, penso eu, a divisão interna de suas aspirações,

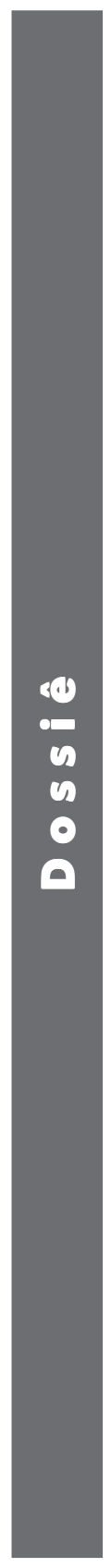


divisão que o levava a buscar ora segurança material (a obtenção de um posto que reabilitasse, além disso, todo seu clã), ora tão-somente a meditação taoísta (o retorno à natureza, ou a recusa da cidade, onde não conseguia estabelecer-se).

O fascínio pelo taoísmo e pela natureza jamais afastou Li Po do vinho, bebida à qual dedicou muitos versos imortais. (Li Po aderira, já se vê, à corrente taoísta que não recusava o álcool.) A bebedeira e o êxtase religioso, assim, muitas vezes se confundem na sua poesia. O vinho, em todo o caso, será explicitamente celebrado como fonte de inspiração poética e assegurará o "êxtase" visual da sua obra. (Poderia ser revelador, penso eu, traçar um paralelo entre o místico Li Po e o materialista Pablo Neruda, já que ambos escreveram versos apaixonados sobre a mesma bebida, sendo, nesse aspecto, iguais: dois grandes literatos boêmios. Não farei, porém, isso agora.)

De tudo o que eu disse até agora, o modo de vida "excêntrico" desse poeta que buscava o "elixir da imortalidade" talvez seja o que mais se evidenciou. No entanto, como também já ficou dito, durante breve período Li Po foi o que se poderia chamar de "poeta laureado", vivendo confortavelmente na esfera da corte imperial. Nem sempre, contudo, ele seguiu o protocolo, e chegou a se apresentar ao imperador, certa vez, em um estado de completa embriaguez foi amparado por terceiros, que lhe deram então banho providencial. Apesar de tudo, conquistou a estima do imperador Xuan-zong, que era também músico (tocava flauta) e conhecia de cor versos do próprio Li Po, os quais chegou a musicar. Às vezes, o poeta compunha de improviso no palácio, e o imperador, em seguida, improvisava a música.

Na verdade, Li Po se destacava também em várias outras áreas além da poesia, e logo redigiu, aspirando a uma função de responsabilidade, um Ensaio sobre a política imperial, tratando de questões da atualidade. Estava decidido a colaborar na consolidação do poder da 
dinastia T'ang. O texto não sobreviveu, mas, segundo os estudiosos, era obra audaciosa e criativa, e tornou-se conhecida em sua época: foi lida na corte e fora dela. Mas a desgraça já lhe rondava as portas. Sem se dar conta, Li Po viu-se envolvido em melindrosa rede de intrigas palacianas, o que o obrigou, finalmente, a afastar-se do poder. Li Po decidiu obter, então, o talismã huo-luo, capaz de destruir os demônios, o que confirmou, mais uma vez, seu apego ao taoísmo.

Por tudo isso, Ferdinand Stoces concluiu, de forma irônica, que, sem dúvida, Li Po aspirava a ser um Imortal, porém na terra e não alhures, no Império Celestial.

Mesmo na velhice, Li Po era o poeta boêmio de sempre, tendo declarado, numa composição célebre no Ocidente, que todos os santos e sábios foram esquecidos na noite dos tempos, mas que os beberrões se tornaram imortais. Aos poucos, ao que parece, o País dos Imortais, com suas ilhas paradisíacas e elixires mágicos, foi-se tornando uma lenda improvável. Sua incredulidade, que não o afastou, no entanto, da vida contemplativa, ele a expressou em vários poemas, chegando a negar, nesses versos tardios, a noção de vida após a morte, ou de imortalidade. Assim, preferiu, no final, dedicar sua atenção à "bebida de jade", que tantas vezes já havia exaltado, a qual representa, ao mesmo tempo, o vinho e o estado de êxtase, mas, obviamente, muito mais do que isso.

Poetas mais sóbrios do que Li Po cantaram de outra maneira o vinho, desmistificando-o, por assim dizer. Yan Wan-li (1127-1206), por exemplo, num dos seus poemas, reconhece que existe uma primavera num vaso de vinho, mas sugere que fosse bebido, num dia especialmente frio, apenas para dar calor ao corpo enregelado.

Li Po também escreveu, convém destacar, o primeiro grande poema chinês sobre o chá - durante a dinastia T'ang, ao lado da poesia, da pintura e da caligrafia, o chá se tornou uma das grandes artes da China. É o nosso poeta, grande bebedor de vinho e chá, quem abrirá, compreensivelmente, a antologia francesa L'extase $d u$ thé, que reúne centenas de poemas dedicados ao tema, desde a época de Li Po até o século 18.

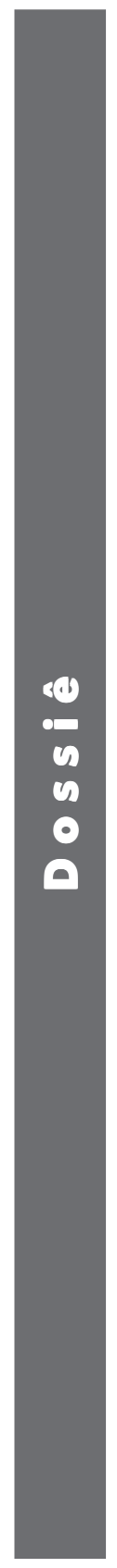


Nos últimos anos de vida, Li Po assistiu a crescente violência política, que culminou, em 756, de maneira insana, em execuções de crianças e adultos. Os membros da família imperial foram tratados com extrema crueldade: depois de assassinados, seus corações foram arrancados do peito e oferecidos em sacrifício ao filho de An Lu-shan (um general rebelde), que o imperador Xuan-zong mandara executar. Tais eventos dramáticos, relacionados a rebeliões e reviravoltas políticas, foram devidamente registrados por Li Po, exímio praticante, conforme se sabe, da poesia autobiográfica, na qual documentou o que sucedia a ele mesmo e a sua época.

É nesse momento, quando o mundo desmorona ao seu redor, que será acusado de traição; em seguida, será detido e levado à prisão. (Cabe recordar que, na mesma ocasião - ou seja, em 757 - outro grande poeta da China clássica, o seu amigo Tu Fu, foi também feito prisioneiro.) Depois, o velho Li Po será condenado ao exílio. É o fundo do poço e o fim definitivo de projetos de ascensão social, acalentados por seu pai e por ele mesmo, ao longo dos anos. O célebre poeta declara num poema, em que parece estar dizendo adeus a tudo: "Na minha vida, raramente verti lágrimas, não faço hoje outra coisa."

Tudo isso fez que sua fé taoísta ficasse ainda mais forte, o que, evidentemente, tendia a tornar irrisório, ou nulo, todo resquício de desejo de glória e poder na capital do império. Mas o destino, como se verá, ainda lhe reservaria uma surpresa.

Li Po é, finalmente, anistiado e, mais uma vez, vê-se às voltas, como enfatiza seu biógrafo, com o dilema de levar uma vida de prazeres ou buscar a senda contemplativa, dedicada ao aprimoramento espiritual. No caminho de volta, deixa-se tocar pela magia da natureza, mas também se entrega aos êxtases da bebida, da música e dos jogos poéticos... O literato boêmio e bon vivant ressurge íntegro, na mesma viagem em que busca reaproximar-se da família. 
Caberia esclarecer, agora, o paradeiro, entre tantas bebedeiras, andanças, rebeliões políticas..., dos manuscritos do poeta. Um poeta de vida tão errante e atribulada não poderia, evidentemente, carregá-los sempre consigo. Perdeu muitos deles, como se sabe, pelos caminhos da velha China.

Li Po tinha profunda confiança em Wei Hao, a quem, já em 754, havia entregue seus manuscritos, com a solicitação de que os organizasse, visando sua reprodução pelos copistas e ampla difusão. Em 759, deu cópias de suas obras ao monge Zhen-qian, outro homem de confiança. Doente, rodeado de vários manuscritos, Li Po ainda tentou ele mesmo pôr ordem nesse emaranhado de textos, agora com o auxílio de um admirador, Li Yang-bing.

Inesperadamente, Li Po obteve um sonhado cargo oficial: foi nomeado censor imperial. Com a saúde muito abalada, morreu sem saber dessa conquista, que coroaria a luta de uma vida inteira, em 10 de novembro de 762, longe de seus familiares.

Quase nada do que eu disse até aqui sobre a vida de Li Po consta do volume Escrito sobre jade, de Haroldo de Campos, poeta que se propôs a traduzir seus poemas, sem mencionar, nas notas explicativas e nos comentários, dados biográficos, exceto aqueles indispensáveis para contextualizar historicamente, em poucas linhas, o autor chinês. No entanto, a escolha dos textos traduzidos nos permite, de certa maneira, acompanhar a vida e a carreira do "Imortal exilado na terra", o que só comprova, parece-me, o acerto das escolhas do tradutor. Essa característica do trabalho de Haroldo de Campos - fazer o recorte certo, ainda que extremamente enxuto - não é menos relevante do que a qualidade poética em si de cada texto produzido por ele.

Sendo assim, ao ler os breves textos de Escrito sobre jade, o leitor vai se deparar com versos que falam, previsivelmente (se considerarmos a biografia de Li Po), da paisagem chinesa e do rosto da mulher, da lua, da nostalgia, da montanha, da viagem e da despedi$\mathrm{da}$, da noite e das persianas de cristal, de pessegueiros em flor e da chuva, de bambus e de pinhos, das nuvens e da taça de vinho (es-

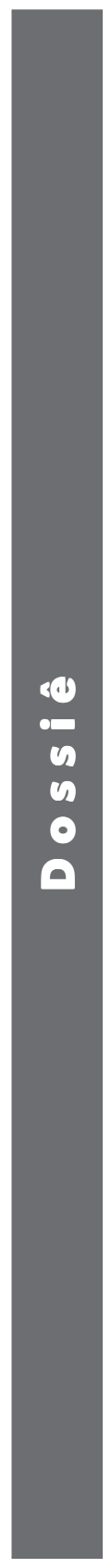


sência de jade), de dragões e de tigres, de ministros e de eremitas, da alegria e da primavera, do canto e da dança, da embriaguez e da Via Láctea...

É conhecida a parábola do homem que se propôs a tarefa de desenhar o mundo e povoou, ao longo dos anos, um espaço de imagens variadas, como talvez as elencadas acima, que retirei das traduções de Haroldo de Campos. Conclui Borges (1953) ao final do texto dessa parábola: "Poco antes de morir, descubre que ese paciente laberinto de líneas traza la imagem de su cara."

Relendo os oito pequenos poemas que constam da seção " $\mathrm{Li}$ Po", da antologia Escrito sobre jade, vislumbro de fato, de maneira sucinta e eficaz, as peripécias reais e imaginárias (ou fragmentos eloqüentes delas, expostos numa ordem não-cronológica) da vida desse personagem imortal que foi Li Po, como só podemos entrever freqüentando seus versos. $\mathrm{O}$ rosto de $\mathrm{Li} \mathrm{Po}$, certamente o melhor rosto de Li Po que temos, hoje, em língua portuguesa, é esse labirinto de linhas, ou versos. Naturalmente, Li Po em português é um personagem híbrido, pois não deixará de refletir, também, Haroldo de Campos, que usou, e dispôs no papel, as palavras de uma maneira muito peculiar. Os versos em questão são, em suma, fielmente haroldianos, e, assim, retomando Mallarmé, poderia afirmar que "Li Haroldo" nos é oferecido, em Escrito sobre jade, "Tel qu'en lui-même enfin l'éternité le change".

O poema que abre a seção referida, por exemplo, e que começa assim: "nuvens / são / cambraias...", já constava, quase idêntico, em tradução de Haroldo de Campos, da "Mini-antologia do paideuma poundiano", que integra a versão brasileira do livro $A B C$ da literatura, de Ezra Pound, lançado muitas décadas atrás no Brasil.

Nessa primeira versão, o poema traz, como título, a palavra Improviso (em itálico), e cada estrofe começa com inicial maiúscula. Tudo isso foi eliminado da versão que integra a seção "Li Po", que estou comentando. Haroldo de Campos purificou, por assim dizer, o poema de seus excessos iniciais. Os versos adquiriram, poderia concluir, em português, a sua concisão clássica, oriental, meta expli- 
citamente perseguida e anunciada pelo tradutor em Escrito sobre jade. Eis o texto:

nuvens

são

cambraias

pétalas

tuas

faces

brisa

que farfalha

nas varandas

altas

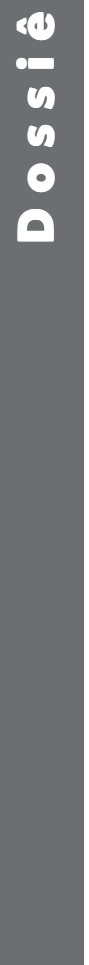

se não posso

vê-la

nos píncaros

de jade

sob a lua

ei-la

no pavilhão

de jaspe 
Na edição anterior de Escrito sobre jade, publicada pela Tipografia do Fundo de Ouro Preto, em 1996, o poema já aparece na forma "limpa", "radical", reproduzida acima: trata-se, portanto, do formato final e definitivo da tradução. (Mais à frente comentarei as diferenças - substanciais - entre a edição de 1996 e a edição de 2009.) Ao comentar suas técnicas de traduzir, ou de "transcriar", ou de "reimaginar" o original, Haroldo de Campos afirma que segue e radicaliza a lição de Ezra Pound, que buscava sempre a concisão, enquanto outros tradutores, como Claudel, citado por ele, procuravam, ao contrário, alongar e expandir o original. Como o próprio Haroldo de Campos admite em Hagoromo de Zeami, estudo e tradução de uma das peças mais famosas do repertório do teatro nô japonês, o seu método se qualificaria, antes, como hiperpoundiano, pois intencionalmente radicaliza os procedimentos do poeta norte-americano, adotando ainda, pode-se também afirmar, as técnicas de espacialização "concretistas". Compare-se, por exemplo, sua antologia Escrito sobre jade com Cathay, de 1915, que consta, em versão mais acessível ao leitor, do conhecido volume Personae: the shorter poems, de Ezra Pound. (Quem não lê nessa língua poderá consultar, em português, a seção "Cathay", do volume Poesia, de Ezra Pound.) Pound não faz aí, é óbvio, o uso sistemático da composição em caixa-baixa, opção exclusiva de Haroldo de Campos. Além disso, talvez seguindo agora a lição dos Cantos poundianos, o tradutor brasileiro incorporou, ao último poema da série, pictogramas originais, conseguindo um tocante e deleitável diálogo entre línguas tão diferentes entre si, como se o português anfitrião se contaminasse definitivamente do seu hóspede chinês, vendo-o, tocando-o, abraçando-o. Trata-se, a meu ver, dentre as recriações, ou reimaginações, sempre felizes, assinadas por "Li Haroldo", do mais belo poema de Escrito sobre jade.

Citarei apenas um fragmento desse texto, a parte que aparece entre parênteses, os quais, à guisa de ideograma oriental, reproduzem o evoluir da lua no céu e do seu reflexo na água. Bêbado e solitário, o poeta dança com a própria sombra: 
(mas a lua é sóbria

e em vão

a sombra me arremeda)

Aproveito para lembrar que certa antologia francesa de versos de Li Po se intitula, justamente, Buvant seul sous la lune. Inclui, como o leitor descobrirá, os versos acima.

Já mencionei a edição de 1996. Mais breve, ela não traz, por exemplo, a seção intitulada "A torre do grou amarelo de Li Po a Mao Tse-tung", que enriquece sobremaneira a edição de 2009. Nela, o líder revolucionário chinês do século 20 dialoga com o passado, compondo poemas à moda clássica e aproximando-se, inesperadamente, de nomes da poesia da dinastia T'ang, como Ts'ui Hao e o próprio Li Po. Os dois poetas foram contemporâneos e o segundo chegou a ficar mudo de admiração ao ouvir um poema composto pelo primeiro.

Essa prática, posta a nu por Haroldo de Campos, de um poeta contemporâneo se referir, em suas composições, a um poeta antigo, era costumeira na poesia clássica chinesa. Longe de ser prova de fraqueza, ela demonstrava, ao contrário, a grande cultura, a erudição do poeta. Assim procedeu Li Po, que adotou os modelos do passado, embora ele nem sempre citasse abertamente suas referências. Estaria ele - indaga Ferdinand Stoces - tão profundamente habitado por essa obra, essa personalidade, que não teria mais consciência da sua influência? Ou seria, antes, um refinamento levado ao extremo, porque suporia que o leitor-ouvinte - também ele cultivado saberia discernir as referências mais sutis?

Contudo, é preciso também lembrar que houve poetas clássicos, como o já citado Yang Wan-li, nascido em 1127, que declararam explicitamente em seus poemas que não desejavam mais imitar os 
mestres do passado, pois buscavam uma iluminação súbita como início do processo poético. Yang Wan-li é famoso por haver declarado que, tendo decidido não mais copiar ninguém, sentia-se finalmente livre para criar. Há, nisso, certamente, uma motivação taoísta, implicando, como tantas vezes expressou o próprio Li Po, uma atitude de sinceridade e integridade que se traduziria num deixar-se levar pelo curso natural das coisas, ganhando importância, então, a realidade imediata e a plenitude do instante presente. "Toda a minha vida eu escutei a chuva", escreveu Yang Wan-li, dentro desse espírito.

Outro texto poético a ser destacado, não apenas porque revela a qualidade estética das traduções de Haroldo de Campos, mas também a dimensão de sua erudição, elevada pelo tradutor a instrumento imprescindível, é o breve e misterioso "O refúgio dos cervos", de Wan Wei. Na tradução de Haroldo de Campos lemos, após o título:

$$
\begin{array}{ll}
\text { montanha vazia } & \text { não se vê ninguém } \\
\text { ouvir só se ouve } & \text { um alguém de ecos } \\
\text { raios do poente } & \text { filtram na espessura } \\
\text { um reflexo ainda } & \text { luz no musgo verde }
\end{array}
$$

Esse poema já foi traduzido numerosas vezes no Ocidente. Haroldo de Campos conhecia certamente muitas versões. A bibliografia citada ao final do volume atesta o quanto a pesquisa é requisito básico para a boa tradução da poesia clássica chinesa. No caso do poema citado, porém, o tradutor brasileiro foi auxiliado, e muito, por um livro precioso, 19 ways of looking at Wang Wei, de Eliot Weinberger e Octavio Paz, que reúne, como sugere o título, várias versões desse poema de quatro linhas, de mais de 1200 anos, escrito por um poeta tão famoso e importante quanto Li Po, e que são assinadas por tradutores tão diferentes, como, entre outros, Gary Snyder, François Cheng, Kenneth Rexroth, G. Margouliès etc. O próprio 
Octavio Paz propõe tradução em espanhol, cujo terceiro verso, "Por los ramajes la luz rompe", embora não seja estritamente literal, é considerado o mais bonito de todas as versões, por Weinberger, crítico exigente.

Aprecio, particularmente, a versão de Gary Snyder. Acredito que a esse elenco de ilustres versões agora podemos acrescentar, com justiça, a de Haroldo de Campos.

\section{Referências}

BORGES, Jorge Luis. "Epilogo" in El hacedor, Buenos Aires: Columba, 1953. CAMPOS, Haroldo de. Escrito sobre jade: poesia clássica chinesa. São Paulo: Ateliê Editorial, 2009.

. Hagoromo de Zeami. São Paulo: Estação Liberdade, 2006.

Escrito sobre jade: poesia clássica chinesa. Ouro Preto: Tipografia do Fundo de Ouro Preto, 1996.

CHENG, Wing Fun e COLLET, Hervé (orgs.). L'extase du thé. Millemont: Moundarren, 2002.

DEMIÉVILLE, Paul (org.). Anthologie de la poésie chinoise classique. Paris: Gallimard, 1962.

LI PO. Buvant seul sous la lune. Millemont: Moundarren, 1999.

POUND, Ezra. Personae: the shorter poems. Nova York: New Directions Books, 1990.

. Poesia. São Paulo e Brasília: Hucitec/Universidade de Brasília, 1983. $A B C$ da literatura. São Paulo: Cultrix, s/d.

STOCES, Ferdinad. Le ciel pour couverture, la terre pour oreiller: la vie et l'oeuvre de Li Po. Arles: Éditions Philippe Picquier, 2006.

WEINBERGER, Eliot e PAZ, Octavio. 19 ways of looking at Wang Wei. Kingston: Asphodel Press, 1987.

YANG Wan-Li. Le son de la pluie. Millemont: Mounderren, 2008. 